\title{
ZINC REPLACEMENT IN HEPATIC ENCEPHALOPATHY AMONG THE EGYPTIAN PATIENTS
}

\author{
By \\ Mohamed Noshy Al-Alfy, Amin Mahmoud Amin Hegazy, Kamel \\ Soliman Hammad*, Ahmed Farouq El-Sayed Shehata \\ Departments of Internal Medicine and Clinical Pathology, Faculty of Medicine, Al-Azhar \\ University, Cairo, Egypt \\ E-mail: ahmedfsayed73@gmail.com
}

\begin{abstract}
Background: Nutritional supplementation may affect the outcomes of liver cirrhosis. Zinc deficiency is common among patients with liver cirrhosis.
\end{abstract}

Objectives: To reveal the impact of zinc replacement therapy in the severity, frequency, and outcomes of hepatic encephalopathy (HE) among a sample of Egyptian patients.

Patients and Methods: Patients aged more than 18 years and had decompensated liver disease and developed HE regardless of its grade were included in the current study. Patients were categorized into three groups based on the serum level of zinc and whether patients received zinc replacement therapy or not.

Results: An overall 90 patients with decompensated liver disease as a sequel of HCV were enrolled in the present investigation. Patients were furtherly assorted based on the presence of zinc deficiency and replacement therapy into three groups. The mean ages of the included patients were 52.3 $\pm 4.7,47.23 \pm 4.7$, and 41.35 \pm 4.28 among groups 1, 2, and 3, respectively. Patients with zinc deficiency and received zinc replacement therapy experienced better outcomes in the terms of short ICU stay and total hospital stays, in contrast to patients within groups 2 and 3 .There was a statistically significant negative correlation between the levels of Zinc and the frequency of HE.

Conclusion: Patients developed HE should receive a comprehensive treatment protocol including zinc replacement therapy even if they have normal zinc levels in order to ameliorate the catastrophic sequels of HE.

Keywords: Hepatic encephalopathy, zinc, replacement.

\section{INTRODUCTION}

Hepatic encephalopathy (HE) is a life menacing complication among patients with liver cirrhosis, which had a prevalence rate of 50 to $70 \%$ worldwide (Yanny et al., 2019). Egypt is one of the most prevalent nation's suffering from chronic liver diseases (Abd El-Salam et $a l ., 2018)$. Hepatic encephalopathy is one of the leading consequences, which influence the prognosis and outcomes of more than $35 \%$ of such patients (Soodand Wong, 2019).

HE is a complex and reversible neuropsychiatric condition that occurs as a sequel of acute or chronic liver disease (Yu et al., 2019). HE may arise spontaneously but more commonly develop as a result of some precipitating factor. Early identification of precipitating 
factors is extremely important in the diagnosis and treatment of this fatal condition (Lok and Bajaj, 2019). Lower serum zinc level has also been seen as a predisposing factor for HE (Alsahhar \& Rahimi, 2019 and Gonzalez-Regueiro et al., 2019).

Zinc is considered as a cofactor of urea cycle enzymes and acts as coenzyme that mediate biogenic amine synthesis and metabolism herein, zinc deficiency may lead go alteration in neurotransmitters like Ý amino-butyric-acid and norepinephrine. Zinc deficiency can result in a spectrum of clinical manifestations (Meena et al., 2019 and Shen et al., 2019). The liver is the main organ responsible for zinc metabolism, and various liver diseases may be influenced by zinc deficiency. Thus, zinc deficiency may be manifested clinically with various symptoms such as poor appetite, loss of body hair, altered taste and smell, delayed wound healing, testicular atrophy, immune dysfunction and diminished drug elimination capacity. Several studies investigated the link between zinc and HE, albeit the overall evidence regarding the effects of zinc therapy for HE remains inconsistent (Shen et al., 2019 and Yanny et al., 2019).

The current study was carried out to reveal the impact of zinc replacement therapy in the severity, frequency, and outcomes of HE among a sample of Egyptian patients.

\section{PATIENTS AND METHODS}

The current study was implemented in coordination with the guidelines of the Declaration of Helsinki. Ethical approval was gained according to the recommendations of Ethics Unite, Faculty of Medicine, Al-Azhar University, Cairo, Egypt. The clinical steps and possible adverse events were plainly demonstrated for all candidates. All patients or their legal trustee assigned informed consents before the enrollment in the study.

The Study was a prospective comparative case-control study, which was implemented throughout the period between March 2017 and March 2018 at the Internal Medicine Department, Bab El-Sharia University Hospital, Al-Azhar University.

\section{Inclusion and exclusion criteria:}

Patients aged more than 18 years, and had decompensated liver disease and developed HE regardless of its grade, were included in the current study. On the other hand, patients with acute confusional state for any reason instead of HE and patients with history of shunt surgery in whom chronic hepatic encephalopathy more prevalent were excluded from the study. In this concern, patients with hepatocellular carcinoma, acute or chronic diarrhea as well as malabsorption syndrome were omitted from the study. Patients receiving zinc replacement for any reason or patients with acute inflammatory conditions or chronic illnesses other than chronic liver disease were excluded.

All candidates were subordinated to through history taking with further concern to reveal the onset, duration, and course of the cirrhotic liver, and DM with focusing on the precipitating factors of HE. Consequently, we performed general and abdominal examination to assess the manifestations of liver cell failure (e.g. jaundice, pallor, ascites, hepatomegaly, splenomegaly, lower limb edema and 
asterixis) as well as grading of HE. The severity of HE was graded based on the clinical manifestations (Vilstrup et al., 2014).

To ensure the optimal assessment, all participants were submitted to liver function tests including; serum albumin, prothrombin time and INR. In addition, liver enzymes, total and direct bilirubin, renal function test (blood urea and serum creatinine), and viral markers were implemented for all patients. Plasmazinclevels were assessed prior to anti-hepatic encephalopathy treatment initiation, whereas plasma zinc levels $<60 \mu \mathrm{g} / \mathrm{dl}$ were considered to be zinc deficiency. Child-Pugh classification was done on admission by using the parameters of serum bilirubin, serum albumin, prothrombin concentration, hepatic encephalopathy, and ascites according to Child-Pugh score system (Kok and Abraldes, 2019). All patients received the usual regimen for management of hepatic encephalopathy and were followed up during the period of hospitalization. Patients who received zinc replacement therapy at a daily dose of 150 $\mathrm{mg}$ orally for 3 months were enrolled in Group (1).

Patients were categorized into three equal groups:

- Group 1: Patients with zinc deficiency (detected by screening before any management starts) and furtherly received zinc replacement.

- Group 2: Patients with zinc deficiency (detected by screening before any management starts) and did not receive zinc replacement.
- Group 3: Patients without zinc deficiency (detected by screening before any management starts).

The determined parameters were the time taken for resolution, the entire hospitalization duration, the need for MICU admission, the development of chronic liver disease-related complications and mortality (if occurred) during hospitalization. All patients were monitored clinically at suitable regular intervals through the outpatient clinic visits over the next 3 months to determine the prognosis in this period of time regarding the recurrence of hepatic encephalopathy.

\section{Statistical analysis:}

Continuous variables were explicated in the form of mean, and standard deviation (SD), and its related groups were compared using one-way Analysis of Variance (ANOVA). On the other hand, continuous non-normally distributed data were reported using median and range and their groups were compared using Kruskal- Wallis test. Categorical variables were expressed using number, and percentage and its particular groups were compared using Pearson's chi-square test. Furthermore, correlation analysis was conducted using Pearson correlation coefficient for continuous normally distributed data, whilst Spearman's rank correlation coefficient was used for other variables. The significance was established when $\mathrm{P}<0.05$. Statistical analysis was performed using SPSS software version 23 for Windows (SPSS Inc., Chicago, IL, USA), and MedCalc software version 14.8 (MedCalc Software, Mariakerke, Belgium). Post- hoc test was 
used with ANOVA for multiple comparisons.

\section{RESULTS}

The mean age of the included patients was $52.3 \pm 4.7,47.23 \pm 4.7$, and $41.35 \pm 4.28$ among groups 1,2 , and 3 , respectively $(\mathrm{p}=0.71)$. There was a statistically significant difference between the three groups regarding the staging of esophageal varices, whereas $11(36.6 \%)$ patients had grade II esophageal varices as opposed to 9 and 2 patients among groups II $(3.3 \%)$ and $3(10 \%)$, respectively. There was no statistically significant difference between the included patients regarding the degree of ascites $(\mathrm{p}=0.87)$, history of bleeding $\quad(\mathrm{p}=0.82)$, and child-Pugh classification $(\mathrm{p}=0.21$, Table 1$)$.

Table (1): Patients demographic characteristic

\begin{tabular}{|c|c|c|c|c|}
\hline $\begin{array}{l}\text { Groups } \\
\text { Parameters }\end{array}$ & Group 1 & Group 2 & Group 3 & P-Value \\
\hline Age (Mean \pm SD) & $52.3 \pm 4.7$ & $47.23 \pm 4.7$ & $41.35 \pm 4.28$ & $>0.0001$ \\
\hline Sex (Male) & $17(56.6 \%)$ & $15(50 \%)$ & $15(50 \%)$ & $>0.05$ \\
\hline \multicolumn{5}{|l|}{ Esophageal Varices } \\
\hline No & $10(33.3 \%)$ & $4(13.3 \%)$ & $11(36.6 \%)$ & \multirow{6}{*}{$<0.001$} \\
\hline I & $7(23.3 \%)$ & $8(26.6 \%)$ & $12(40 \%)$ & \\
\hline II & 0 & 0 & $4(13.3 \%)$ & \\
\hline II & $9(30 \%)$ & $11(36.6 \%)$ & $2(6.6 \%)$ & \\
\hline III & $3(10 \%)$ & $6(20 \%)$ & $1(3.3 \%)$ & \\
\hline IV & $1(3.4 \%)$ & $1(3.3 \%)$ & 0 & \\
\hline \multicolumn{5}{|l|}{ Degree of Ascites } \\
\hline Mild & $9(30 \%)$ & $6(20 \%)$ & $6(20 \%)$ & \multirow{3}{*}{$>0.05$} \\
\hline Moderate & $17(56.6 \%)$ & $19(63.3 \%)$ & $19(63.3 \%)$ & \\
\hline Severe & $4(13.3 \%)$ & $5(16.6 \%)$ & $5(16.6 \%)$ & \\
\hline History of bleeding & $10(33.3 \%)$ & $12(40 \%)$ & $12(40 \%)$ & $>0.05$ \\
\hline \multicolumn{5}{|c|}{ Child - pugh classification } \\
\hline $10 \mathrm{C}$ & $9(30 \%)$ & $7(23.3 \%)$ & $3(10 \%)$ & \multirow{8}{*}{$>0.05$} \\
\hline $11 \mathrm{C}$ & $4(13.3 \%)$ & $8(26.6 \%)$ & $5(16.6 \%)$ & \\
\hline $12 \mathrm{C}$ & $5(16.6 \%)$ & $8(26.6 \%)$ & $10(33.3 \%)$ & \\
\hline $13 \mathrm{C}$ & $3(10 \%)$ & $5(16.6 \%)$ & $6(20 \%)$ & \\
\hline $14 \mathrm{C}$ & $2(6.6 \%)$ & $1(3.3 \%)$ & 0 & \\
\hline $15 \mathrm{C}$ & $2(6.6 \%)$ & 0 & $2(6.6 \%)$ & \\
\hline $8 \mathrm{~B}$ & 0 & $1(3.3 \%)$ & 0 & \\
\hline 9B & $5(16.6 \%)$ & 0 & $4(13.3 \%)$ & \\
\hline
\end{tabular}

There was no statistically significant difference between the included patients in groups 1, 2, and 3 in the levels of ALT $(\mathrm{P}=0.52)$, AST $(\mathrm{P}=0.67)$, total bilirubin $(\mathrm{P}=0.059)$, direct bilirubin $(\mathrm{p}=0.63)$, serum albumin $(\mathrm{p}=0.519)$, and platelet count $(\mathrm{p}=0.39)$. On the other hand, there was a statistically significant higher level of ammonia among group 2
(111.63 \pm 48.14$)$, in contrast to groups 1 (98.26 \pm 37.7$)$, and group $3(68.178 \pm 15.67)$ $(\mathrm{p}<0.001)$. Besides that, the mean levels of zinc were significantly high among patients within group 3 (78(60-90)), in contrast to groups 1 and 2 with a median of 28.5 (5-57) and 24.5(3-53), respectively (Table 2). 
Table (2): Laboratory assessment of the included patients (mean \pm SD)

\begin{tabular}{|c|c|c|c|c|c|}
\hline \multirow{2}{*}{$\begin{array}{lll}\text { Parameters } & \text { Groups } \\
& \end{array}$} & Group 1 & Group 2 & Group 3 & $\begin{array}{l}\text { One-way } \\
\text { ANOVA }\end{array}$ & $\begin{array}{c}\text { P- } \\
\text { Value }\end{array}$ \\
\hline & & & & & \\
\hline ALT(ù-I) & $79.4 \pm 24.7$ & $49.66 \pm 6.9$ & $79.85 \pm 25.25$ & 20.7 & 0.5 \\
\hline AST(ù-I) & $78.73 \pm 22.6$ & $46.2 \pm 8.2$ & $80.178 \pm 22.6$ & 29.11 & 0.67 \\
\hline Total Bilirubin(mg-dl) & $2.62 \pm 1.04$ & $2.09 \pm 0.96$ & $2.6 \pm 1.01$ & 2.92 & 0.059 \\
\hline Direct Bilirubin (mg-dl) & $1.45 \pm 1.63$ & $1.12 \pm 0.59$ & $1.46 \pm 0.55$ & 2.86 & 0.63 \\
\hline Serum Albumin(mg-dl) & $2.686 \pm 0.41$ & $2.57 \pm 0.37$ & $2.67 \pm 0.42$ & 0.662 & $>0.05$ \\
\hline Serum Urea(mg-dl) & $18.96 \pm 3.05$ & $18.93 \pm 3.38$ & $18.82 \pm 3.1$ & 0.0011 & $>0.05$ \\
\hline Serum Creatinine(mg-dl) & $0.84 \pm 0.17$ & $0.853 \pm 0.2$ & $0.84 \pm 0.17$ & 0.049 & $>0.05$ \\
\hline Platelet count $(\mathrm{K}-\mu \mathrm{L})$ & $118.06 \pm 35.7$ & $107.66 \pm 29.8$ & $117.67 \pm 37.05$ & 0.93 & 0.39 \\
\hline Prothrombin time (Sec) & $16.6 \pm 1.81$ & $15.06 \pm 1.52$ & $16.53 \pm 1.85$ & 7.919 & $<0,001$ \\
\hline INR & $1.59 \pm 0.64$ & $1.88 \pm 0.57$ & $1.94 \pm 0.62$ & 2.68 & 0.074 \\
\hline Ammonia $(\mu-d \mathrm{l})$ & $98.26 \pm 37.7$ & $111.63 \pm 48.14$ & $68.178 \pm 15.67$ & 11.08 & $<0.001$ \\
\hline Zinc $(\mu \mathrm{g} / \mathrm{dl})$ & $28.5(5-57)$ & $24.5(3-53)$ & $78(60-90)$ & $59.47 *$ & $<0.001$ \\
\hline
\end{tabular}

Patients with zinc deficiency and received zinc replacement therapy (Group 1) experienced better outcomes in the terms of short ICU stay $(2.66 \pm 0.8)$ and total hospital stays $(5.86 \pm 0.93)$, in contrast to patients within groups 2 and 3
( $\mathrm{p}<0.001)$. In this concern, $27(90 \%)$ patients received zinc supplementation had no new HE attacks with three month after treatment, in contrast to $20(66 \%)$ patients with groups $3(\mathrm{p}<0.001)$ (Table 3).

Table (3): Assessed outcomes among the included patients

\begin{tabular}{|c|c|c|c|c|c|}
\hline $\begin{array}{l}\text { Groups } \\
\text { parameters }\end{array}$ & Group 1 & Group 2 & Group 3 & $\begin{array}{l}\text { One-way } \\
\text { ANOVA }\end{array}$ & P-Value \\
\hline ICU Stay (Days) & $2.66 \pm 0.8$ & $5.33 \pm 1.12$ & $3.75 \pm 1.55$ & 104.77 & $<0.001$ \\
\hline $\begin{array}{l}\text { Hospital stay } \\
\text { (Days) }\end{array}$ & $5.86 \pm 0.93$ & $10.63 \pm 1.8$ & $6.53 \pm 1.2$ & 104.77 & $<0.001$ \\
\hline \multicolumn{6}{|c|}{ Frequency of HE 3 month after Zinc replacement } \\
\hline No attacks & $3(10 \%)$ & $2(6.6 \%)$ & $5(6.6 \%)$ & & \\
\hline 1 & 0 & $11(36.6 \%)$ & $5(6.6 \%)$ & & \\
\hline 2 & 0 & $11(36.6 \%)$ & 0 & & \\
\hline 3 & 0 & $6(20 \%)$ & 0 & & \\
\hline 4 & 0 & $6(20 \%)$ & 0 & & \\
\hline
\end{tabular}

There was a statistically significant negative correlation between the levels of Zinc and the frequency of HE after three months $(r=-0.59, p=0.02)$. Similar to that, there was a statistically significant negative correlation between the levels of zinc and total hospital stays ( $\mathrm{r}=-0.30$, $\mathrm{p}=0.03$ ). Additionally, there was a statically significant negative correlation between the levels of zinc and ammonia $(r=-0.692, p<0.001$ - Figures 1 and 2). 


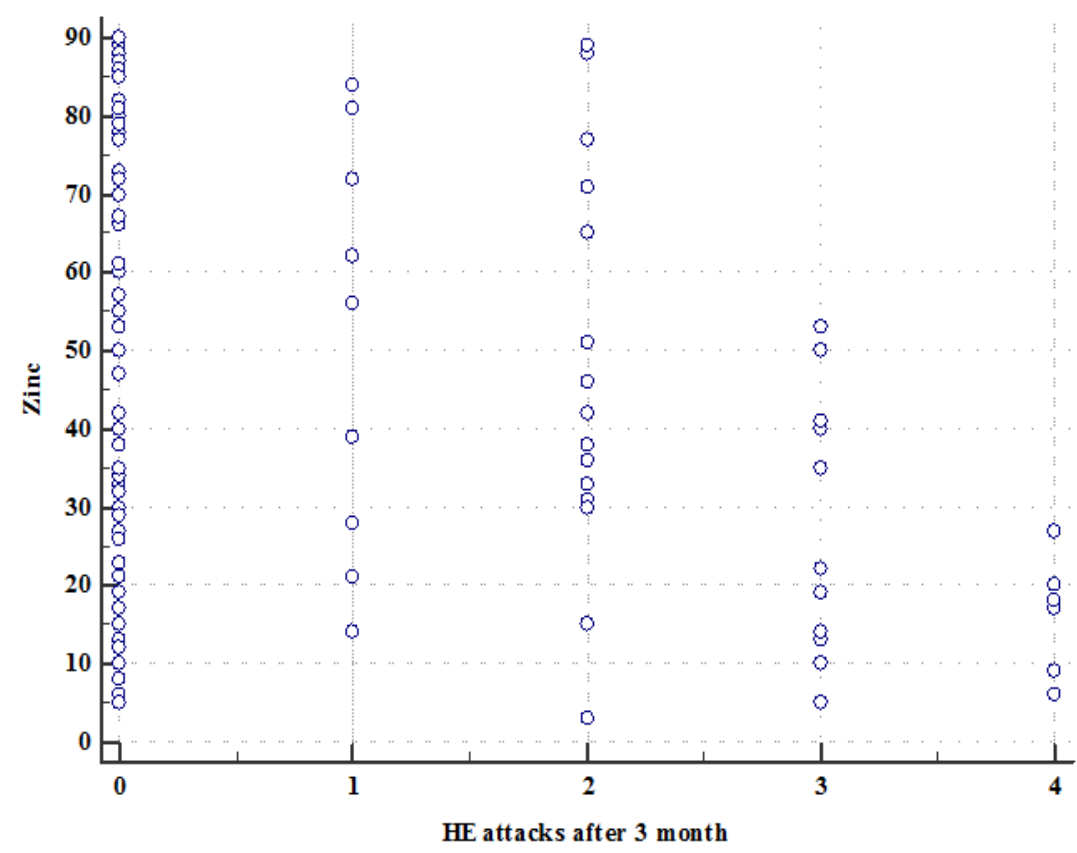

Figure (1): Correlation between zinc levels and frequency of $\mathrm{HE}$ after three months

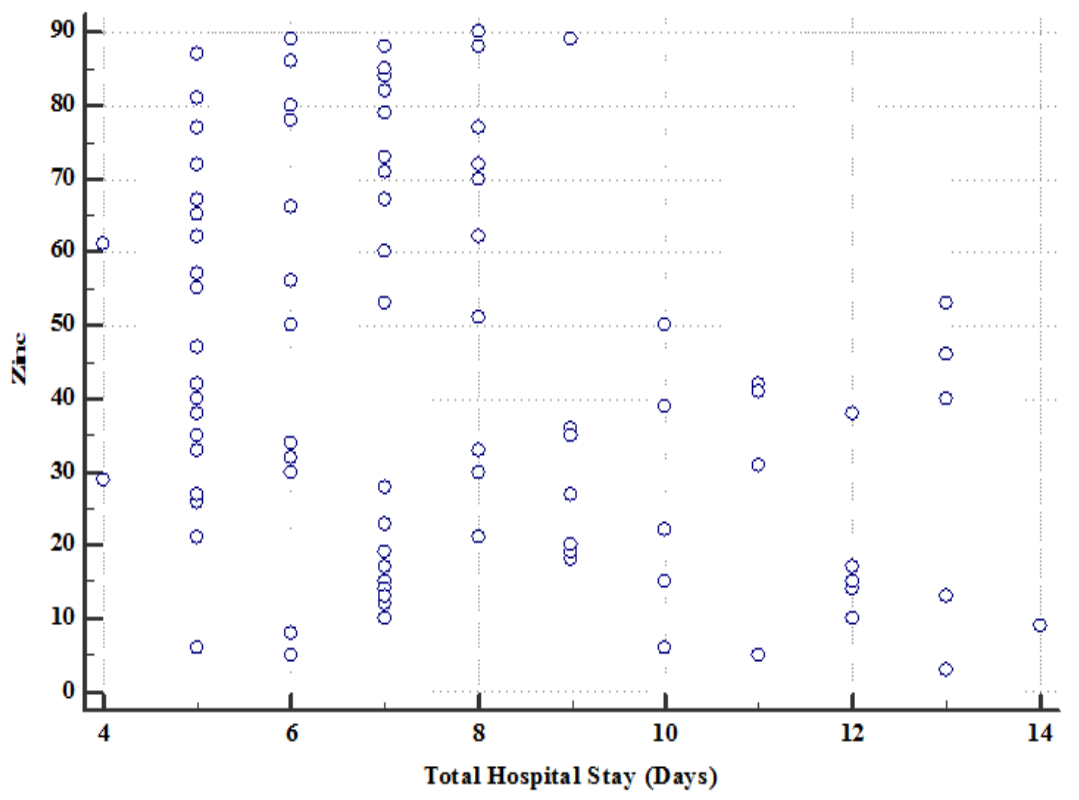

Figure (2): Correlation between zinc levels and total hospital stays (days)

There was a statistically significant negative correlation between the levels of zinc and total hospital stays $(\mathrm{r}=-0.30$, $\mathrm{p}=0.03$ - Figure 3). 


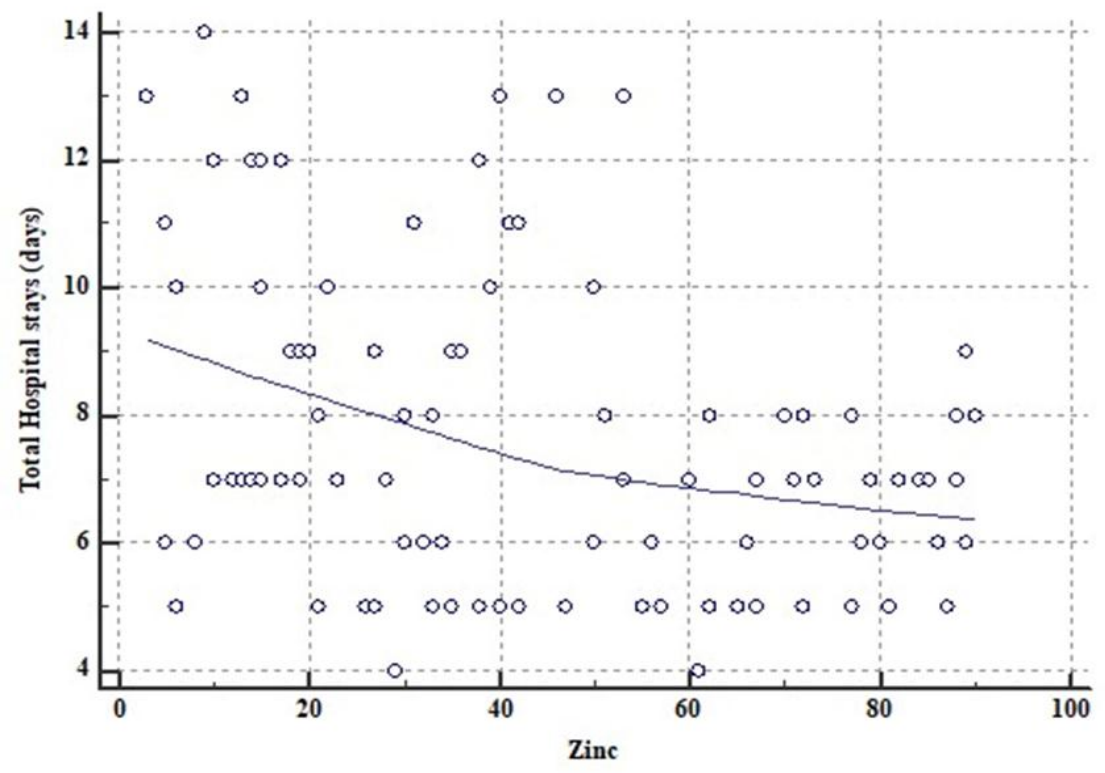

Figure (3): Correlation between zinc levels and total hospital stays (days)

There was a statistically significant negative correlation between the levels of

Zinc and the frequency of HE after three months ( $r=-0.59, p=0.02$ - Figure 4).

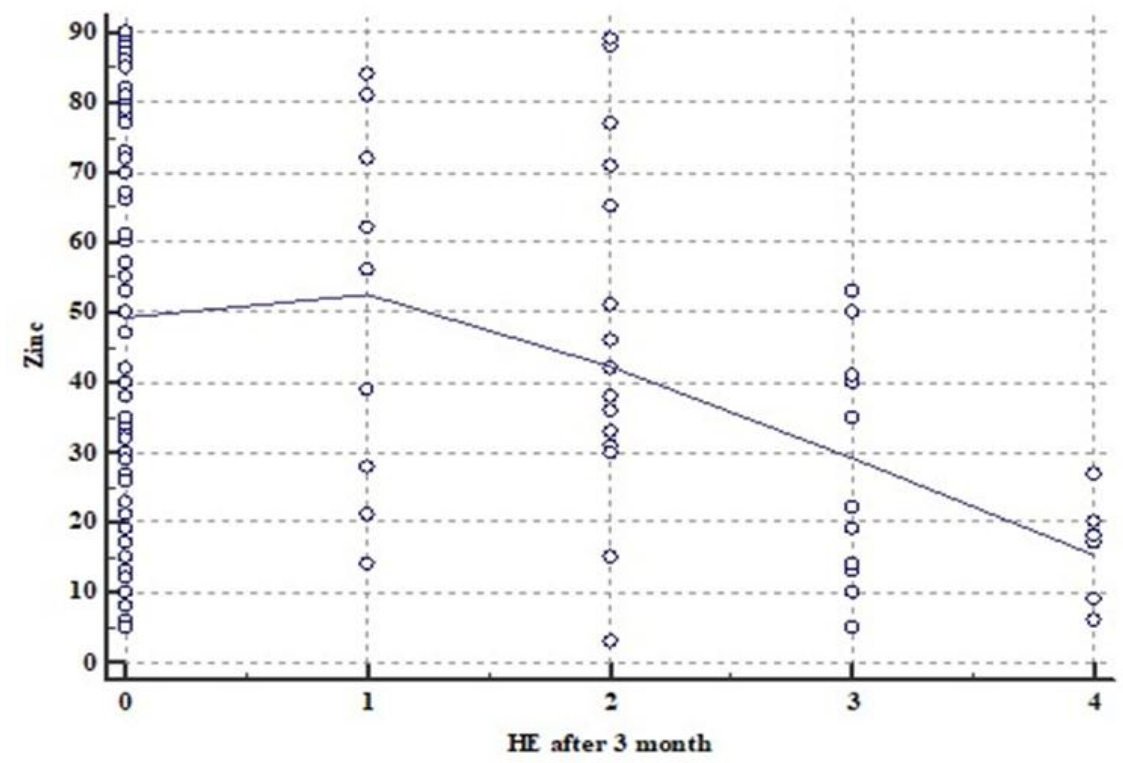

Figure (4): Correlation between zinc levels and HE after 3 months

\section{DISCUSSION}

Patients with decompensated liver disease are supposed to suffer from zinc deficiency, which may contribute to the progression of clinical manifestations (Plotnikova et al., 2015). As a sequel, HE impacted considerably the patient's quality of life such as working capabilities, longer hospitalization, and eventually death. Such conditions might be improved by zinc replacement therapy. Conversely, the current literature was still limited regarding the long-term outcomes 
of zinc replacement therapy among decompensated liver disease patients (Yanny et al., 2019). Thereafter, the current study was performed to reveal the outcomes of zinc replacement therapy after three month from replacement therapy.

In the current study; patients with decompensated liver disease and zinc deficiency accomplished better outcomes in the terms of frequency of HE attacks, shorter hospital stays, and shorter ICU stay. Not only these results were superior to patients with zinc deficiency and did not receive replacement therapy, but they also were better than the results obtained by patients with normal serum zinc levels. Based on these findings, health care providers should employ a routine supplementation of zinc even if among patients with normal serum zinc levels.

Zinc deficiency is likely to occur in patients with liver cirrhosis, and factors that are potentially responsible for such zinc deficiency include disturbed zinc absorption by the digestive tract and increased zinc excretion in the urine. Further, diuretics, which are commonly used to treat edema and ascites, aggravate zinc deficiencies in patients with liver cirrhosis by increasing zinc excretion in the urine (Chiba et al., 2013).

It has been suggested that zinc deficiency is related to the pathogenesis of hepatic encephalopathy. Several studies have shown a statistically significant inverse relationship between the serum levels of zinc and ammonia (Meena et al., 2019). These results were concomitant with our study which revealed a negative correlation between the levels of serum zinc and the frequency of $\mathrm{HE}$ at three month.

On the basis of these findings, several studies have examined the effects of zinc supplementation in patients with hyperammonemia (Katayama et al., 2011). In accordance with our findings, Shen et al., reported that additional zinc supplementation may have a significant effect on the neurological outcomes when compared with lactulose therapy alone in cirrhotic patients with mild HE Similar to that, Mousa et al., notified a significant improvement was reported in patients with HE after 3 months of antioxidant and zinc therapy in contrast to patients received lactulose therapy (group B) (p $<0.001$ - Mousa et al., 2016).

In particular, these results might attribute to the evolving of our findings. Physical manifestations in HE patients presumably were tremor, ataxia, asterisks and ascites; consequently, improvements in these manifestations via zinc supplementation might correlate with change in psycho-neurological outcomes (Mousa et al., 2016).

The present study had numerous limitations, which may alter its results. For instance, the lack of randomization and the absence of sample randomization and calculation may have a potential effect on the evidence of the study.

\section{CONCLUSION}

Patients developed HE should receive a comprehensive treatment protocol including zinc replacement therapy even if they have normal zinc levels in order to ameliorate the catastrophic sequels of HE. However, quasi-randomized or highly randomized clinical trials with proper 
calculation of sample size are necessary to overcome the co-existing limitations of the present investigation.

\section{REFERENCES}

1. Abd-Elsalam, S., Elwan, N., Soliman, H., Ziada, D., Elkhalawany, W., Salama, M. and Shehata, W. M. (2018): Epidemiology of liver cancer in Nile delta over a decade: A single-center study. South Asian Journal of Cancer, 7(1):12-19.

2. Alsahhar, J. S. and Rahimi, R. S. (2019): Updates on the pathophysiology and therapeutic targets for hepatic encephalopathy. Curr Opin Gastroenterol., 35(3): 145-154.

3. Chiba, M., Katayama, K., Takeda, R., Morita, R., Iwahashi, K., Onishi, Y.and Saito, T. (2013): Diuretics aggravate zinc deficiency in patients with liver cirrhosis by increasing zinc excretion in urine. Hepatology Research, 43(4): 365-373.

4. Gonzalez-Regueiro, J. A., Higuera-de la Tijera, M. F., Moreno-Alcantar, R.and Torre, A. (2019): Pathophysiology of hepatic encephalopathy and future treatment options. Rev Gastroenterol Mex., 84(2): 195-203.

5. Katayama, K., Sakakibara, M., Imanaka, K., Ohkawa, K., Matsunaga, T., Naito, M.andIto, T. (2011): Effect of zinc supplementation in patients with type $\mathrm{C}$ liver cirrhosis. Open Journal of Gastroenterology, 1(02):12-23.

6. Kok, B.and Abraldes, J. G. (2019): ChildPugh Classification: Time to Abandon? Seminars in liver disease,39(1) :96 - 103 Thieme Medical Publishers.

7. Lok, A. S. and Bajaj, J. S. (2019): Diagnosis and Treatment of Hepatic Encephalopathy. Hepatol Commun. 15(8): 434-436.

8. Meena, R. K., G, S., Saravanan, P., P, K., Ramadoss, K. and A, V. (2019): Serum Zinc Level in Decompensated Liver Disease and its Correlation with Stage of Hepatic Encephalopathy. J Assoc Physicians India, 67(1), 30-32.
9. Mousa, N., Abdel-Razik, A., Zaher, A., Hamed, M., Shiha, G., Effat, N. and ElWakeel, N. (2016): The role of antioxidants and zinc in minimal hepatic encephalopathy: a randomized trial. Therapeutic Advances in Gastroenterology, 9(5): 684-691.

10. Plotnikova, E. Y., Baranova, E. N.and Maksimov, S. A. (2015): Hepatic encephalopathy and tissue zinc levels in liver disease, diagnosis and treatment. Eksp Klin Gastroenterol., 7:46-54.

11. Shen, Y.-C., Chang, Y.-H., Fang, C.-J. and Lin, Y.-S. (2019): Zinc supplementation in patients with cirrhosis and hepatic encephalopathy: a systematic review and meta-analysis. Nutrition Journal, 18(1):12-26.

12. Sood, K. T. and Wong, R. J. (2019): Hepatic Encephalopathy is a Strong Predictor of Early Hospital Readmission Among Cirrhosis Patients. J Clin Exp Hepatol., 9(4): 484-490.

13. Vilstrup, H., Amodio, P., Bajaj, J., Cordoba, J., Ferenci, P., Mullen, K. D and Wong, P. (2014): Hepatic encephalopathy in chronic liver disease: 2014 Practice Guideline by the American Association for the Study of Liver Diseases and the European Association for the Study of the Liver. Hepatology, 60(2): 715-735.

14. Yanny, B., Winters, A., Boutros, S. and Saab, S. (2019): Hepatic Encephalopathy Challenges, Burden, and Diagnostic and Therapeutic Approach. Clin Liver Dis., 23(4): 607-623.

15. Yu, H., Chen, Y. and Jiang, P. (2019): Prognostic value of hepatic encephalopathy for survival of patients with liver failure: A systematic review and meta-analysis. Nutr. J. 18(4): 607-612. 


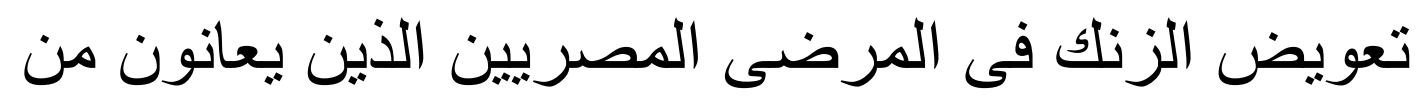

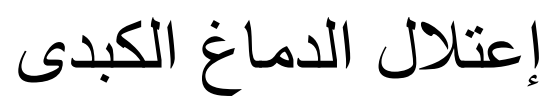

محمد نصحى الألفى، أمين محمود أمين حجازى - كامل سليمان حماد*ـ أحمد فاروق السيا شحاتة

قسم الأمراض الباطنة العامة والباثولوجيا الإكلينيكيةث، كلية الطب، جامعة الأزهر

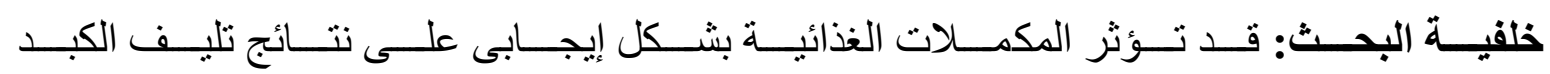

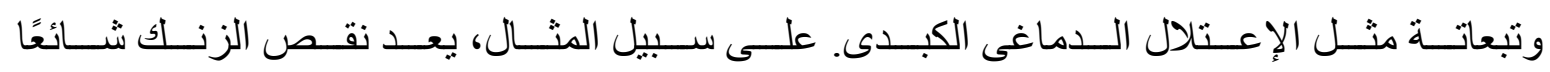
بين مرضى تليف الكبد.

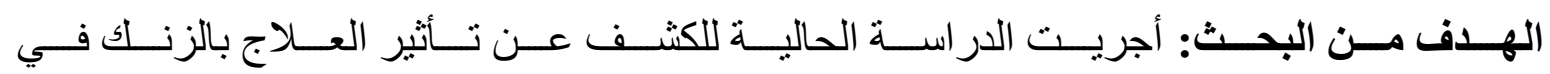
شدة ونتائج اعتلال الدماغ الكبدي بين عينة من المرضى المصريت الكرين.

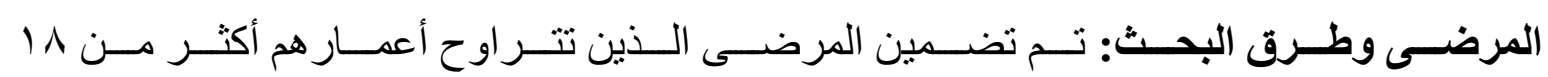

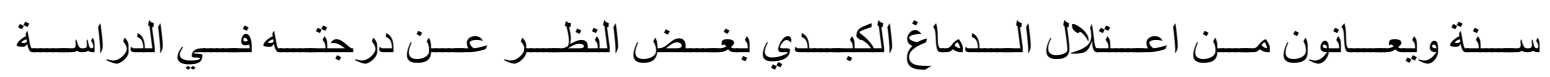

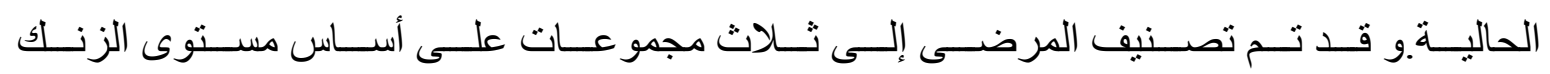
و وما إذا كان المرضى تلقو ا علاج الزنك أم لا.

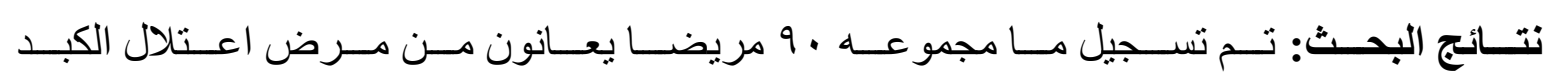

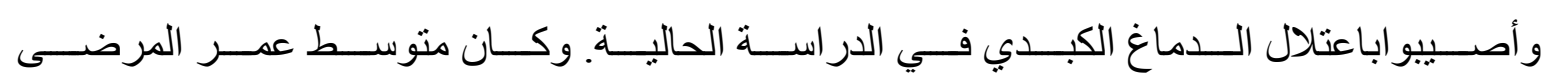
المشــــــــ

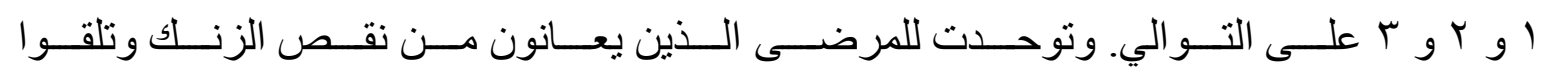

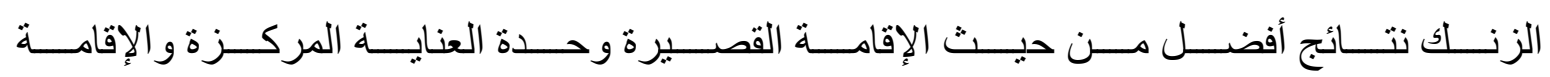

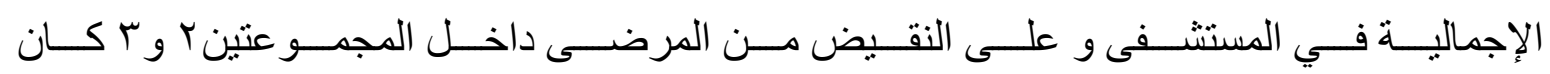

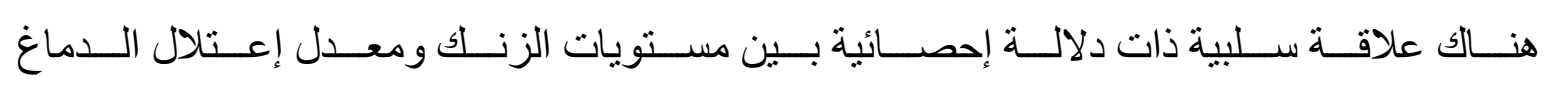
الكبدي ومستوى الامونيا بالدم.

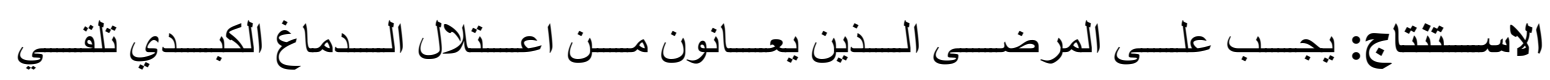

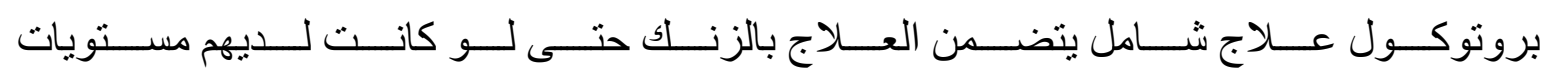
الزنك الطبيعية من أجل تخفيف الآثار الكارثية من اعتلال الدماغ الكبدي. 